\title{
Otonom Kara ve Hava Araçları ile Akıllı Tarım: Hasat Optimizasyonu Üzerine Bir Uygulama1
}

\author{
Alparslan GÜZEY* $\quad$ Mehmet Mutlu AKINCI ${ }^{* *} \quad$ Şenol ALTAN****
}

Geliş Tarihi (Received): 19.04.2020 - Kabul Tarihi (Accepted): 11.05.2020

\section{Öz}

Günümüzde tarım sektörü yeni şirketler ve yatırımcılarla bir yüksek teknoloji endüstrisi haline gelmektedir. Teknolojinin hızlı gelişmesi sadece çiftçilerin üretim yeteneklerini geliştirmeyip, robotik ve otomasyon teknolojisini de geliştirmektedir. Çiftçiler artık hasat toplamada otonom hava araçları ve robotlar kullanarak üretim verimlerini artırmaktadırlar. Bu çalışmada, birbirleriyle iletişim halinde otonom insansız hava ve kara araçlarına tarım arazisinde hedefleri daha önceden belirlenmiş elmaların zaman minimizasyonu ile hasat toplatılması amaçlanmıştır. Mevcut çalışılan problemin çok büyük olmasından dolayı süre optimizasyonu yapılması amacıyla ana problem küçük alt problemlere bölünerek çözülmüştür. Kara araçlarının duraklarının yerlerinin belirlenmesi ve bu yerlerin belirlenme işlemini çözümlemek için kortalama kümeleme yönteminden yararlanılmıştır. Hesaplamalar için ise Julia programlama dili kullanılmıştır. Çalışmada örnek olarak toplatılması düşünülen 500 elma için optimal durak sayısı 3 olarak bulunmuştur. Her bir durakta hava araçlarının elma toplama sürelerini optimize etmek için hazırlanan model ise Gurobi çözücüsü yardımıyla çözümlenip sonuçlara ulaşılmıştır. Çalışmanın sonucunda kara aracının her bir durakta ortalama bekleme süresi yaklaşık 439 sn olarak elde edilmiştir.

Anahtar Kelimeler: Otonom Araçlar, Akıllı Tarım, K-Ortalama Yöntemi, 0-1 Tamsayılı Programlama, , Optimizasyon

\footnotetext{
1 Bu makale, Şubat 2020 tarihinde 20. Uluslararası Ekonometri, Yöneylem Araştırması ve İstatistik Sempozyumunda sözlü bildiri olarak sunulan çalışmanın genişletilmiş hali olup, TUBİTAK 217 E138 numaralı proje kapsamında desteklenmiştir.

Y. Lisans Öğrencisi, Ankara Hacı Bayram Veli Üniversitesi, Lisansüstü Eğitim Enstitüsü, alparslanguzey@gmail.com.

** Dr. Öğr. Üyesi, Erzurum Teknik Üniversitesi, mehmet.akinci@erzurum.edu.tr.

*** Prof. Dr., Ankara Hacı Bayram Veli Üniversitesi, Ekonometri Bölümü, senol.altan@ hbv.edu.tr.
} 


\title{
Smart Agriculture with Autonomous Ground and Air Vehicles: An Application on to Harvest Optimization
}

\begin{abstract}
Today, the agricultural sector is becoming a high-tech industry with new companies and investors. Rapid development of technology not only improves farmers' production capabilities, but also improves robotics and automation technology. Farmers are now increasing their production efficiency by using autonomous aircraft and robots in harvesting. In this study, it is aimed to collect the harvest by the time minimization of the previously determined apples in the agricultural land in communication of autonomous unmanned aerial and ground vehicles. Due to the fact that the current problem is very large, the main problem is solved by dividing it into small sub-problems in order to make time optimization. K-means clustering method was used to determine the locations of the ground vehicles' stops and to analyze it. Julia programming language is used for calculations. In the study, the optimal number of stops for 500 apples was found to be 3 . The model prepared to optimize the apple picking times of air vehicle at each stop was resolved with the help of the Gurobi solvent and the results were achieved. As a result of the study, the average waiting time of the ground vehicle at each stop was approximately 439 seconds.
\end{abstract}

Keywords: Autonomous Vehicles, Smart Agriculture, K-Means Method, 1-0 İteger Programming, Optimization 


\section{Giriş}

Meyve hasadı; elle, yarı mekanize ve tam mekanize şeklinde üç farklı yöntemle yürütülmektedir. Ülkemizde özellikle taze tüketilen meyvelerin hasadında elle hasat sıkl1kla başvurulan bir yöntemdir. Elle hasatta mekanik zedelenmelerin az olması ürünün ihraç edilebilmesi açısından önemli bir avantajdır. Buna rağmen meyvelerin elle hasadının toplam iş gücü gereksinimine ve toplam maliyetlere etkisi oldukça fazladır. İşçiler, toplam hasat süresinin büyük kısmını meyveye uzanım ve koparma süresinde harcamaktadır. Hasatta merdiven kullanılması halinde ise zamanın büyük bölümünün merdiven taşınması ve kurulması sırasında harcanmasından dolayı iş verimi azalmaktadır. Bu durum işçiyi enerji tüketimi yönünden aşırı yüklemekte ayrıca merdiven kullanımından kaynaklanan kazalar da meydana gelmektedir. $\mathrm{Bu}$ nedenle, araştırmacılar işçiyi daha iyi ve güvenli bir iş ortamında çalıştıracak yardımcı araçların geliştirilmesine yönelmişlerdir (Eminoğlu, 2015: 233).

Günümüzde tarım sektörü yeni şirketler ve yatırımcılar aracılığıyla heyecan verici bir yüksek teknoloji endüstrisi haline gelmektedir. Teknoloji hızla gelişmekte ve bu gelişen teknoloji sadece çiftçilerin üretim yeteneklerini geliştirmekle kalmayıp, robotik ve otomasyon teknolojisini de geliştirmektedir. Bu gelişmenin temelinde önemli ölçüde artan ve ivmeli olarak önümüzdeki yıllarda daha da artacak olan yiyecek ve temel gıda ihtiyacı yatmaktadır. Birleşmiş Milletler, dünya nüfusunun 7,3 milyardan 2050 yılında 9,7 milyara yükseleceğini tahmin etmektedir. Bu nüfus artışıyla doğru orantılı olarak dünyanın çok daha fazla yiyeceğe ihtiyacı olacak ve çiftçiler bu talebi karşılamak için ciddi baskılarla karşı karşıya kalacaklardır. Tarımda verimliliği artırmak için üretim verilerinin toplanması, daha sonra bu verilerin analiz edilmesi ve tarım işçiliğinin robotlar ve otomasyon sistemleri aracılığıyla yapılması gerekmektedir. $\mathrm{Bu}$ çalışmada otonom sistemlerin birbirleriyle iletişim halinde tarım arazisinde elma hasadı toplanması amaçlanmıştır. Elma, portakal, şeftali, armut ve avokado gibi meyveleri hasat etmek için büyük emek ve işgücü gerekir. İş gücü, aslında, bu meyveleri üretmede çiftçinin en büyük harcama kalemini oluşturur. Taze ürünlere olan talebin arttığı günümüz dünyasında, tarım işçilerinin sayısı azalırken, çiftçiler için akıllı tarım ve hasat robotları maliyet ve işgücünü azaltıp üretim kapasitesini artırmaya yönelik en etkin çözümdür.

\section{Meyve Hasatı, Akıllı Tarım ve Kullanılan Otonom Hasat Toplama Araçları}

Meyve hasat platformları, elle hasat sirasında insan hareketini azaltmak, toplama dışındaki süreyi en aza indirmek ve optimum çalışma koşullarına ulaşmak amacıyla kullanılır. 
$\mathrm{Bu}$ platformların kullanımı başka bir ifadeyle hasat süresi boyunca verimliliğin artırılmasını sağlamaktadır.

Tarımın gelecek zamanlarda büyüyen bir dünya nüfusu için daha az kaynakla sağlanacak olan sürdürülebilir uygun fiyatlarla daha fazla gıda ve yakıt üretmek gibi zorluklarla karşı karşıya kalması muhtemeldir. Bu zorlukların üstesinden gelmede akıllı tarımdan faydalanılacaktır. Akıllı tarım unsurlarının kullanımıyla, maliyetler düşerken faydalar artmakta ve daha sürdürülebilir bir tarım gelişimi ile çiftçilere çevresel zorlukların üstesinden gelme ve artan bir nüfusu beslemek için gıda üretim seviyelerinin sürdürülmesine yardımcı olunabilecek çözümler sunulmaktadır.

Akıllı tarım, kaynak açısından daha verimli ve kesin bir yaklaşıma dayanarak daha üretken ve sürdürülebilir bir tarımsal üretim sağlama potansiyeline sahiptir. Akıllı tarım, üreticiye daha iyi karar verme veya daha verimli bir işletme operasyonları ve yönetimi şeklinde katma değer sağlamalıdır. Bu anlamda akıllı tarım, birbirine bağlı yönetim bilgi sistemleri, hassas tarım ve tarımsal otomasyon-robotik gibi üç teknoloji alanı ile güçlü bir şekilde ilişkilidir (Duman ve Özsoy, 2019: 544).

Yönetim bilgi sistemleri, bir çiftliğin faaliyetlerini ve fonksiyonlarını yerine getirmek için gereken biçimde veri toplama, işleme, depolama ve yayma amaçlı planlı sistemlerdir.

Hassas tarım, ekonomik getiriyi iyileştirmek ve çevresel etkileri azaltmak için mekânsal ve zamansal değişkenliğin yönetimidir. Kaynakları koruyarak, droneların havadan görüntülerini ve sentinel uyduları tarafından sağlanan en yeni nesil hiperpektral görüntülerin kullanımı ile mahsul verimi, arazi özellikleri/topografya, organik madde içeriği, nem seviyeleri gibi ölçülebildiği kadar çok değişkenin mekânsal değişkenlik haritalarının oluşturulmasına imkân tanıyarak girdilerin dönüşünü optimize etmek amacı ile karar destek sistemlerini (DSS) içerir. Hassas tarımda, insansız hava araçlarının (İHA) algılama ve görüntüleme platformları ile tarım amaçlı kullanımı, uydu teknolojisi ile yakından algılama, akıllı sensörler ile uygulamalar, mevcuttur. Ayrıca tabletlerde ya da el bilgisayarı için bilgisayar yazılımları, taşınır arazi tipi bilgisayarlar, kablosuz veri transferi ve iletişim sistemleri, araçtan araca veri iletimi, otonom (kendi yürür) araçlar ve platformlar, robotlar, akıllı makinalar ve bunlara uyumlu donanımlar, hali hazırdaki teknolojik gelişmelerdir (Topakcı ve Ünal, 2010).

Tarımsal otomasyon ve robotik; farmbots ve farmdronelar da dâhil olmak üzere her türlü tarımsal üretimde robotik, otomatik kontrol ve yapay zekâ teknikleri uygulama sürecidir.

Tarımsal robotlar, üreticiler için üretim verimini çeşitli yollarla artırmaktadır. Bunlardan bazıları; otonom İHA'lar, otonom traktörler ve robotik kollardır. Bu teknolojik 
yenilikler yaratıcı ve yenilikçi uygulamalarda kullanılmaktadır. Tarımsal robotlar, çiftçiler için yavaş, tekrarlayan ve sıkıcı görevleri otonomlaştırarak, toplam üretim verimini artırmaya daha fazla odaklanmalarını sağlarlar. Otonom robotlar, kendisine verilen bir görevi yerine getirmek için yöntem bulabilen ayrıca kendisini korumak için sensörler (algılayıcılar) yardımıyla çevreden elde ettiği verileri kullanarak olası tehlikeleri önlemek için statik veya dinamik olarak engellerden korunabilen otonom olarak görevleri yerine getirebilen elektro-mekanik cihazlardır (Tekin, 2013: 273-278).

Tarım sektöründe en yaygın kullanım alanları olan tarımsal robotlar şu şekilde sıralanabilir:

- Hasat ve toplama,

- Zararlı ot kontrolü,

- Otonom biçme, budama, tohumlama, püskürtme ve inceltme,

- Ayırma ve paketleme,

- Hizmet platformları.

ABD'de sadece 2016 yılında 7 milyon tondan fazla elma elle toplanmıştır. Bu zor iş için saatlik ücretler de arttığından, bu sektörde işgücü sıkıntıları da ciddi bir sorun haline gelmektedir.

Hasat ve toplama robotları, neyin seçileceğini belirlemek için görüntü işleme ve robotik kolların bir kombinasyonunu kullanır. Elmanın kalite kontrolü ve derecelendirilmesi ancak tek bir işlemde tekrarlı işlem yapılması önlenerek yapılabilir. Hasat robotu tarafından görüntü işlemesi yapılan ürün hakkındaki veri analizi, iş gelirinin belirlenmesinde, paketleme ve işleme süreçlerinin düzenlenmesinde yardımcı olabilir.

Tarımda nesnelerin internetiyle verimliliğin en üst düzeye çıkarılması hedeflenir. $\mathrm{Bu}$ yapılanmada doğal kaynaklar ihtiyaç olan düzeyde kullanıldığından maliyet düşmektedir. Benzer şekilde çiftlikte bulunan akıllı sistemlerle üretim için gerekli olan tüm faktörler analiz edilmekte ve üreticiye eş zamanlı sunulmaktadır. Bu sayede kaynak israfları önlenmekte ve kaliteli ürünler üretilmektedir. Ayrıca birbirleriyle iletişim halinde olan ve senkronize çalışan makinelerle hızlı karar verme mekanizmaları oluşturulmaktadır. Üreticiye bir tablet ya da telefondan tüm çiftliği yönetebilme ve gözlemleyebilme imkânı verilmekte iş gücü de azaltılarak verimli, eğlenceli, kaliteli ve doğal üretim imkanları oluşturulmaktadır.

Çalışmanın ikinci başlığında alan yazında yer alan otonom hasat toplama hava aracı ve kullanım alanlarına göre çeşitli İHA'larla ilişkili çalışmalardan bahsedilmiştir. Araştırma yönteminin açıklandığı üçüncü başlıkta ise önerilen modelin durak sayısı, toplam bekleme 
süreleri, amaç fonksiyonu ve kısıtlar yer almaktadır. Bulguların yer aldığı dördüncü başlıkta da önerilen modelin uygulaması ve küme yapısı açıklanmaktadır.

\section{Literatür Taraması}

Hasat ve toplama, robotların verim boyutunu artırmak ve tarlada kalan ürünlerden kaynaklanan atıkları azaltmak için elde edebileceği doğruluk ve hız nedeniyle tarımda en bilinen robotik uygulamalardandır.

Günümüzde tarım 4.0 teknolojisinde insansız hava araçları ile hasat toplaması aktif olarak henüz yapılmamakla birlikte ilerleyen yıllarda mevcut teknolojinin tarım 5.0'a evrilmesiyle bu yönde çalışmaların hız kazanacağı öngörülmektedir. Aşağıda verilen Şekil 1'de İsrailli bir firmanın otonom hasat toplama hava aracı ve örnek çizimleri yer almaktadır. Şekil 2'de ise örnek bir otonom hasat toplama hava aracı yer almaktadır.

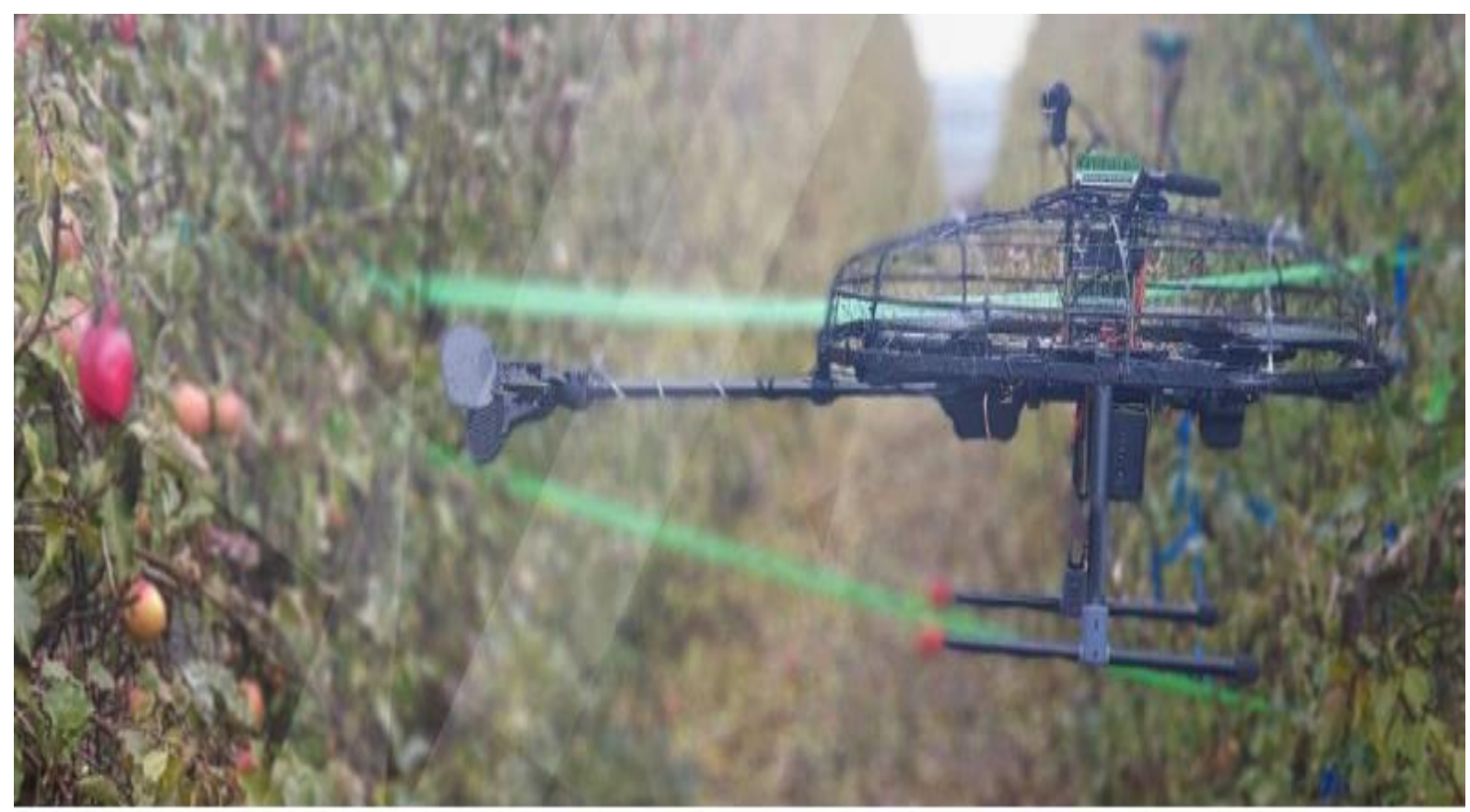

Şekil 1. Otonom Hasat Toplama Hava Aracı

Kaynak: Tevel-tech, 2019.

Alan yazında İHA'ların çeşitli kullanım alanlarına göre, araç rotalama problemlerinin ele alındığı birçok çalışma yer almaktadır.

Murray ve Chu (2015) çalışmalarında ilk olarak kamyon, daha sonra İHA ile son nokta taşıması yapan bir model fikri ortaya koymuşlardır. Bu fikir "Uçan Yardımcı Gezgin Satıcı 
Problemi (Flying Sidekick Traveling Salesman Problem)" olarak adlandırılmıştır. Çalışma kapsamında teslimatlarda bir İHA ve bir kamyon kullanılmıştır. Araçlar aynı anda taşıma yapabilmektedir. Teslimat sonrasında İHA, kamyona geri dönmek zorundadır. Çalışmada karma tamsayılı doğrusal programlama (MILP) ve sezgisel metotlar kullanılmıştır.

Olivares vd., (2015) çalışmalarında, bir imalat fabrikasının iç lojistiğinde, özellikle montaj ve ürünlerin kişiselleştirilmesi aşamasında bir İHA tipi Quadcopterin kullanılması incelenmiştir. Bu çalışmadaki amaç, büyük bir dezavantaj olan işletim sırasında yüksek enerji tüketimini modellemek ve en iyilemektir. Çalışmada depoların, kümelerin ve alt kümelenmelerin yerini belirlemek için bir iç lojistik modellemesi gerçekleştirilmiştir. Bu işleme ek olarak her bir Quadcopter için bir genetik algoritma kullanılarak çeşitli yollar oluşturulmuştur. Ayrıca her bir Quadcopter tarafindan taşınacak ağırlık, malzeme ve rota belirlenmiştir. Son olarak taşınan ağırlığa, ziyaret edilen iş istasyonlarına ve sayılarına göre quadcopter aerodinamik verimliliğine bağlı olarak belirli bir rota için her bir quadcopterin aküsünden boşaltılacak elektrik gücü miktarı da optimize edilmiştir.

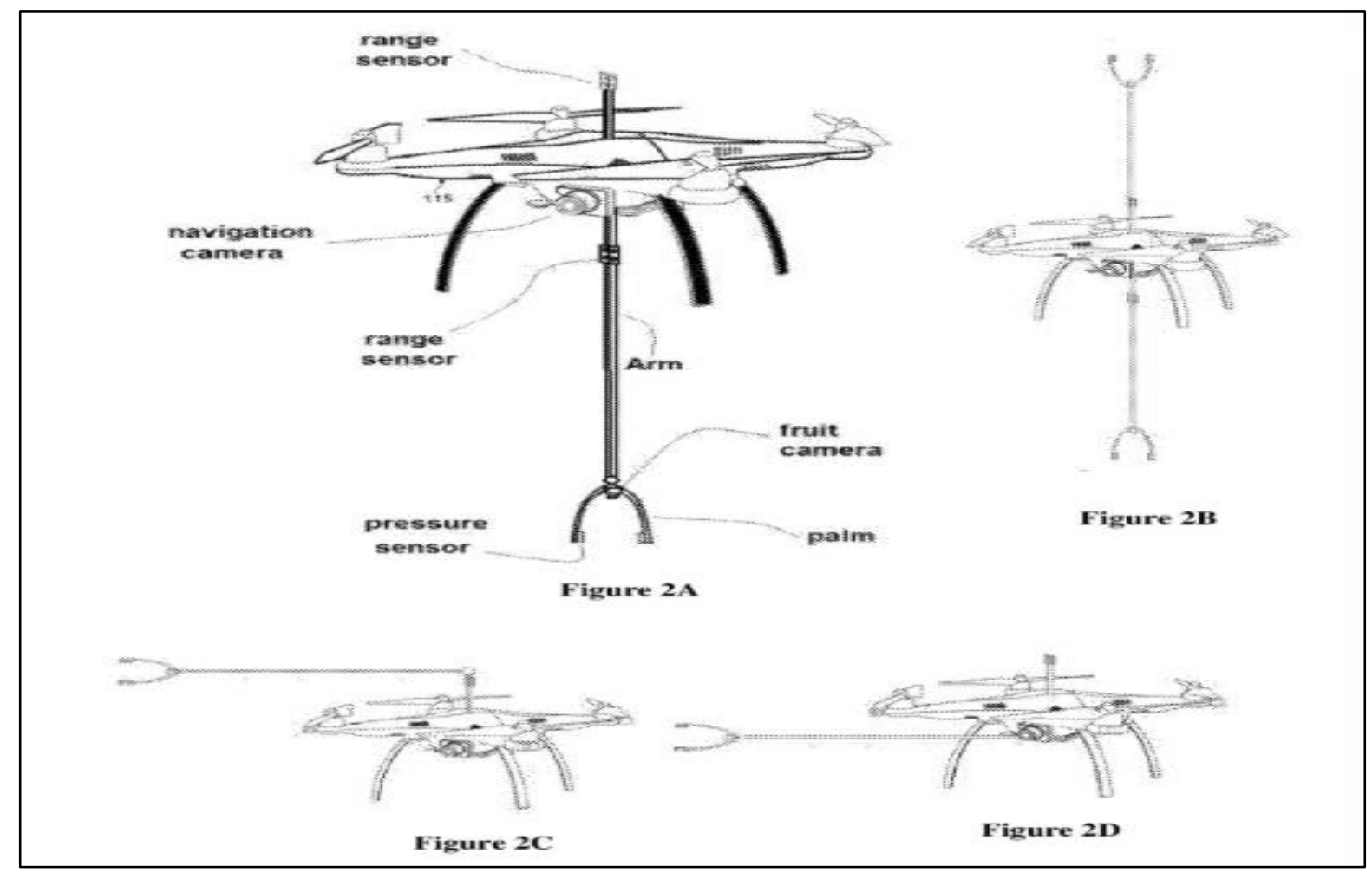

Şekil 2. Örnek Otonom Hasat Toplama Hava Aracı

Kaynak: Tevel-tech, 2019. 
Bekhti vd., (2017) çalışmalarında, otonom İHA’lar için, bölgesel kablosuz ağların izleme kapasiteleri ile yol planlaması yapmışlardır. Çalışmada amaç, en kısa yol ile hedef noktaya ulaşımı minimize etmektir. Bu amacı gerçekleştirirken İHA'nın konum bilgisi kablosuz ağ kullanılarak izlenmiştir. Sonuç olarak, en iyi çözüm bulunamamış ama izlenmek istenen konum bilgisinin doğruluk oranı azaltılarak uygun bir çözüm bulunmuştur.

Wang vd., (2016) tarafından, birden çok kamyon ve İHA'nın olduğu bir sistemde taşıma sürelerinin en iyilendiği “İHA’lar İle Araç Rotalama Problemi” olarak adlandırılan bir çalışma yapılmıştır. Bu çalışmada birçok kötü senaryo incelenmiş, sadece kamyon yerine, hem kamyon hem de İHA'ların kullanıldığı zamandan tasarruflu senaryo önerilmiştir.

\section{Yöntem}

\section{1. Önerilen Optimizasyon Modeli}

$\mathrm{Bu}$ çalışma kapsamında geliştirilen model, problemin iki alt probleme bölünerek modellenmesinden oluşmaktadır. Bunlar sırasıyla en az durak sayısı ile bu durakların konumunun bulunması ve duraklardaki elmaların toplama sürelerinin minimize edilmesidir. Ayrıca yapılan simülasyonlar sonucunda durak sayısının üç gibi çok az olmasından dolayı kara taşıtlarına ilişkin bir modellemeye gerek duyulmamıştır.

\subsubsection{En az durak sayısı ile bu durakların konumlarının bulunması}

Ferrandez vd.,(2016) optimal durak koordinatlarının bulunması için k-ortalamalar yöntemini önermişlerdir. Burada önerilen modelde Ferrandez vd. (2016) çalışmasından faydalanılmıştır. Bu süreç koşullu bir döngü tarafından yönetilmektedir.

En az durak sayısı ile bu durakların konumlarının bulunması işleminde algoritma şu şekilde işlemektedir. Başlangıçta durak sayısı 2 olarak alınmıştır. Elmaların koordinatları kullanılarak k-ortalamalar kümeleme yöntemi kullanılarak elmalar iki kümeye atanarak her bir kümenin merkez noktası elde edilmiştir. Bu merkez noktanın kümedeki en uzak elmaya olan uzaklığı eğer drone'nun toplama alanı(menzili) içerisinde ise döngü sonlandırılmış, aksi durumda ise durak sayısı "1” arttırılarak döngü tekrarlanmıştır.

\subsubsection{Duraklardaki elmaların toplama sürelerinin minimize edilmesi}

Modelde kullanılan indisler Tablo 1'de, parametreler ve tanım kümeleri Tablo 2'de, karar değişkenleri ise Tablo 3'te verilmiştir. Daha sonra kısıtlar ve amaç fonksiyonu açıklanarak optimizasyon modeli kurulmuştur. 
Tablo 1. İndisler, Açıklamaları ve Tanım Kümeleri

\begin{tabular}{llll}
\hline İndis & Açıklama & Tanım Kümesi & \\
\hline$\dot{\mathrm{I}}$ & Elma indisi & $\mathrm{I}=\left\{1,2, \ldots, \mathrm{i}_{\max }\right\}$ & $\mathrm{i}_{\text {max }}:$ Sahadaki toplam elma sayısı \\
\hline $\mathrm{J}$ & Durak indisi & $\mathrm{J}=\left\{1,2, \ldots, \mathrm{j}_{\max }\right\}$ & $\mathrm{j}_{\max }:$ Sahadaki toplam durak sayısı \\
$\mathrm{K}$ & Drone indisi & $\begin{array}{l}\mathrm{K}=\left\{1,2, \ldots, \mathrm{k}_{\max }\right\} \\
\text { toplam drone sayısı }\end{array}$ \\
\hline
\end{tabular}

Tablo 2. Parametreler ve Açıklamaları

\begin{tabular}{ll}
\hline Parametre & Açıklama \\
\hline $\mathrm{A}_{\mathrm{ij}}$ & $\begin{array}{l}\text { A, her bir elmanın hangi durakta toplanması gerektiğini gösteren } \\
\text { bir matristir. Eğer değer "0" ise i. elmanın j. duraktan } \\
\text { toplanmayacağını, " } 1 \text { " ise toplanacağını göstermektedir. }\end{array}$ \\
$\mathrm{U}_{\mathrm{ij}}$ & $\mathrm{U}$, her bir elmanın duraklara olan dakika cinsinden uzaklıkları. \\
\hline
\end{tabular}

Önerilen modele ilişkin karar değişkenleri ve açıklamaları Tablo 3'te sunulmuştur.

Tablo 3. Karar Değişkenleri ve Açıklamaları

\begin{tabular}{ll}
\hline $\begin{array}{l}\text { Karar } \\
\text { Değişkeni }\end{array}$ & Açıklama \\
\hline $\mathrm{D}_{\mathrm{ijk}}$ & $\begin{array}{l}\text { i. elmanın j. durakta k. drone tarafından toplanması durumunda "1”, } \\
\text { toplanmaması durumunda “0” değerini alan bir değişkendir. }\end{array}$ \\
\hline $\mathrm{SE}_{\mathrm{ijk}}$ & $\begin{array}{l}\text { k. dronenun j. Durakta i. elmayı toplamak için harcadığ dakika } \\
\text { cinsinden şarj süresini gösteren sürekli türde bir değişkendir. }\end{array}$ \\
$\mathrm{SD}_{\mathrm{jk}}$ & $\begin{array}{l}\text { k. dronenun j. durakta elma toplamak ve şarj olmak için harcadığı dakika } \\
\text { cinsinden toplam süreyi gösteren sürekli türde bir değişkendir. }\end{array}$ \\
$\mathrm{SDM}_{\mathrm{j}}$ & $\begin{array}{l}\text { Kara taşıtının j. durakta harcadığı dakika cinsinden toplam süreyi } \\
\text { gösteren sürekli türde bir değişkendir. Bu süre droneların j. durakta } \\
\text { toplama ve şarj süresi en fazla olan dronedan elde edilmektedir. }\end{array}$ \\
\hline
\end{tabular}

\subsubsection{Model Kisıtları}

Probleme ilişkin önerilen modeldeki kısıtlar şu şekildedir:

Eşitlik (1)'de verilen kısıt ile her bir elmanın muhakkak herhangi bir durakta, herhangi bir drone tarafından toplanması sağlanmaktadır.

$$
\sum_{j=1}^{j_{\max }} \sum_{k=1}^{k_{\max }} D_{i j k}=1 \quad \forall i \in I
$$


Eşitlik (2)'deki kısıt ile her bir durakta droneların sadece menzilindeki elmaları toplamaları sağlanmaktadır. Drone, elma toplamaya giderken harcadığı süre kadar şarj süresini tüketmektedir. Dönüşte elmayı taşıması sebebiyle drone, harcadığı sürenin \%120'si (30/25) kadar şarj süresi tüketmektedir. Bu nedenle elmanın durağa süre cinsinden uzaklığının 2,2 katı toplam uçuş süresi olan 30 dakikadan az olmalıdır.

$$
2,2 * A_{i j} * U_{i j} * D_{i j k} \leq 30 \quad \forall i \in I, j \in J, k \in K
$$

Eşitlik (2) ile elde edilen değer, Eşitlik (3) ile model içinde k. drone'nun, j. durakta i. elmayı toplamak için harcadığı dakika cinsinden şarj süresini elde etmesi sağlanmaktadır.

$$
2,2 * A_{i j} * U_{i j} * D_{i j k}=S E_{i j k} \quad \forall i \in I, j \in J, k \in K
$$

Eşitlik (4) ile k. drone'nun, j. durakta elma toplamak ve şarj olmak için harcadığı dakika cinsinden toplam süre bulunmaktadır.

$$
\sum_{i=1}^{i_{\max }} 2 * A_{i j} * U_{i j} * D_{i j k}+S E_{i j k}=S D_{j k} \quad \forall j \in J, k \in K
$$

Eşitlik (5) ile drone'ların, j. durakta elma toplama ve şarj süresi en fazla olan drone'nun harcadığı dakika cinsinden toplam süre elde edilmektedir.

$$
S D_{j k} \leq S D M_{j} \quad \forall j \in J, k \in K
$$

\subsubsection{Modelin Amaç Fonksiyonu}

Önerilen model için amaç fonksiyonu Eşitlik (6)'daki gibi oluşturulabilir.

$$
Z_{\min }=\sum_{j=1}^{j_{\max }} S D M_{j}
$$

Eşitlik (6)'da verilen amaç fonksiyonu her bir durakta elma toplama ve şarj süresi en fazla olan drone'nun harcadığı dakika cinsinden toplam süreyi minimize etmeye çalışmaktadır. 


\section{Bulgular}

\subsection{Uygulama}

Bu çalışmada önerilen model, Intel ${ }^{\circledR}$ Core ${ }^{\mathrm{TM}}$ i7-2670QM @ 2,2GHz işlemci ve 6 GB RAM donanımına sahip bir bilgisayarda çözümlenmiştir. Çözümleme için elmaların koordinatlarının oluşturulması, kümelenmesi, uzaklıkların hesaplanması ile matematiksel modelin yazılımı için Julia programlama dili (Bezanson vd., 2017), JuMP paketi (Dunning vd., 2017), JuliaStats/Clustering.jl paketi ve JuliaStats/Distances.jl paketi kullanılmıştır. Modelin çözümlenmesi için ise Gurobi Optimizer (Gurobi Optimization, 2018) yazılımından yararlanılmıştır.

Uygulamada k-ortalama kümeleme yöntemi kullanılmıştır. Bu yöntem eğiticisiz yani veriler sisteme yüklendikten sonra algoritmanın çeşitli sonuçlar çıkarması olarak bilinmektedir. K-ortalama yöntemi kümelerin merkezlerini kullanarak verileri karakterize eder. Bu merkezler, karesi alınmış hataların toplamının minimize edilmesiyle belirlenir. K-ortalamalar yönteminde yakınsama garanti edilene kadar iki önemli adım gerçekleştirilir. Bu adımlardan ilki tüm veri noktaları üzerinden geçmek ve onların en yakın merkezleri için bunları yeniden atamak, ikincisi ise kendilerine verilen puan ortalaması olarak merkezlerini yeniden hesaplamaktır (Şengöz ve Özdemir, 2016: 88).

Uygulamada elma sayısı (imax) 500 ve kara taşıtı üzerindeki drone sayısı (kmax) 5 olarak alınmıştır. Elmaların konumlarını elde etmek için "rand" fonksiyonu ve k-ortalama kümeleme yöntemi için JuliaStats/Clustering.j1 paketi kullanılmıştır. Uçan Yardımcı Gezgin Satıcı (UYGS)'da dağıtım ya da toplama sırasında kara taşıtının hareket halinde olması uygulamada verimsizliğe yol açmaktadır. Bunun da sebebi durak yerinin belirli sayıdaki elmaları toplamak için optimal noktada olmasıdır. Eğer kara taşıtı hareket ederse elmaları toplama işi optimal süreden daha uzun sürecektir. Optimal durak noktalarını bulmak için kortalama kümeleme yönteminden faydalanılmıştır. Bunun sağladığı avantaj ise Şekil 3’te görüleceği üzere kümeleme yöntemiyle elde edilen her bir kümenin merkezinin o kümedeki tüm elmaları toplamak için en ideal konum olmasıdır. Uygulamada hava araçları kendi menzili içerisinde bulunan durağa tahsis edilmekte olup bu koşulu sağlayan en az sayıda durak kullanılmıştır. Tablo 4'te ise belirlenen duraklardaki toplam hasat toplama zamanlarına ilişkin optimal değerler verilmiştir. Elde edilen durakların elmalara olan uzaklıklarının hesaplanması için JuliaStats/Distances.jl paketi kullanılmıştır. Durak sayısı(küme sayısı) ve konumlarının bulunması için yapılan yinelemelerde durak sayısı (jmax) 3 olarak elde edilmiştir. Şekil 3’te 
500 elmaya ilişkin kümeleme yapısı ve duraklar sunulmuştur. Şekilde verilen "X” ler durakları temsil etmektedir.

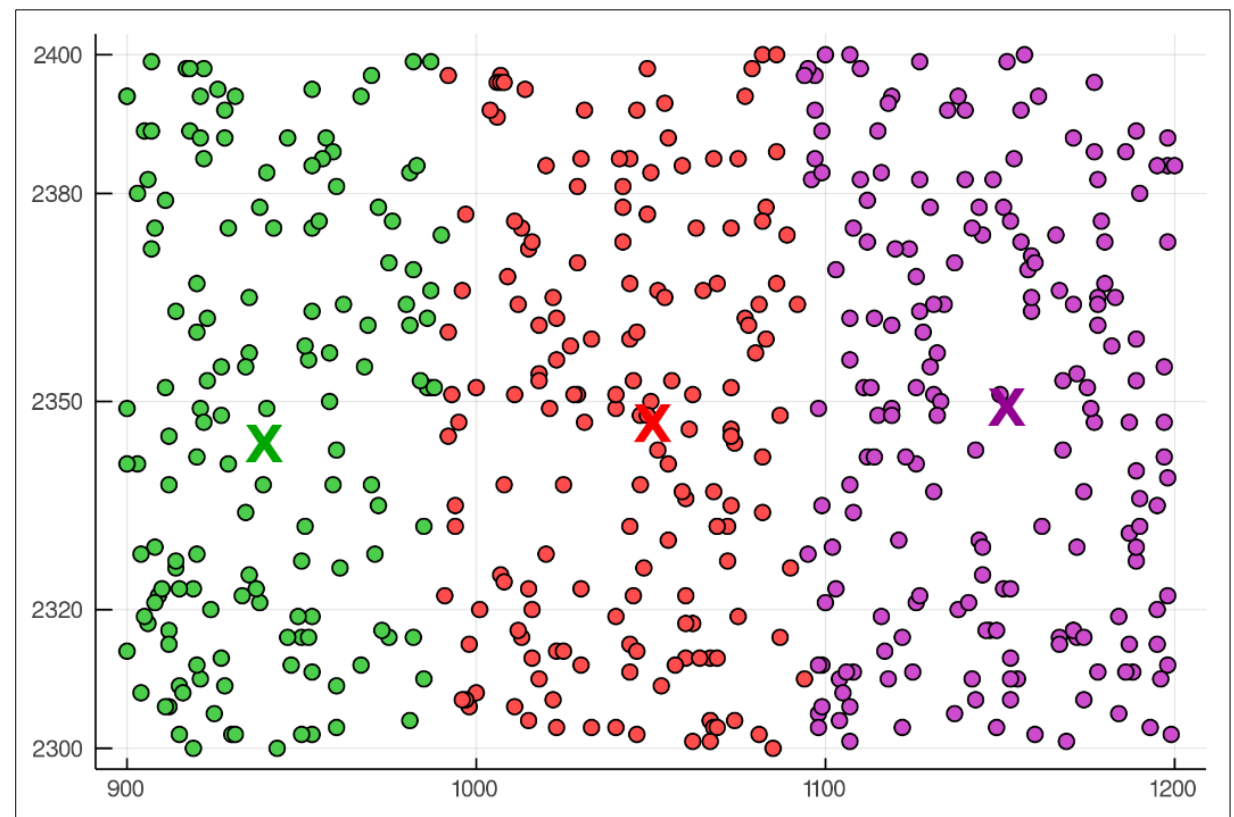

Şekil 3. Küme Yapısı ve Duraklar

Önerilen model uygulama verileri üzerinde denendiğinde elde edilen optimal değerler Tablo 4'te sunulmuştur.

Tablo 4. Duraklara İlişkin Optimal Elma Toplama Süreleri

\begin{tabular}{l|c}
\hline Durak Sayısı(Küme Sayısı) & Optimal Değer (dk) \\
\hline 1. Küme & 581,665 \\
\hline 2. Küme & 490,348 \\
\hline 3. Küme & 312,884 \\
\hline Genel Toplam & 1384,897 \\
\hline
\end{tabular}

Sonuç ve Öneriler

$\mathrm{Bu}$ çalışmada, otonom insansız hava ve kara araçlarının birbirleriyle iletişim halinde tarım arazisinde hedefleri daha önceden belirlenmiş elmaların zaman minimizasyonu ile hasat toplanması amaçlanmıştır. Mevcut çalışılan problemin çok büyük olmasından dolayı süre optimizasyonu yapılması amacıyla ana problem küçük alt problemlere bölünerek çözülmüştür. Kara araçlarının durak yerlerinin belirlenmesi ve bunun çözümlenmesi için k-ortalama 
kümeleme yöntemi kullanılmıştır. Modeldeki karar değişkenleri ve katsayıları azaltmak için her duraktaki tüm elmaların mesafesi yerine sadece mevcut durağa ilişkin kümeye atanmış elmalar yerine konulmuştur. Ayrıca bir seferde tüm durakları optimize etmek yerine, hem aynı sonucu vermesi açısından hem de daha pratik olması sebebiyle, her durağın toplama süresi kendi içerisinde optimize edilmiştir. Hesaplamalar için Julia programlama dili kullanılmıştır. Belirli kriterlere göre elmaların yerlerini gösteren rastgele oluşturulmuş koordinatlar üretilmiştir. Ardından küme sayısı 2 ile başlayarak k-ortalama kümeleme yöntemi kullanılarak merkez noktaları elde edilmiş ve bu noktaların kendi kümesindeki en uzak elmaya olan uzaklığının hava aracının menzilinde olması koşulu sağlanıncaya kadar iterasyon küme sayısı arttırılarak devam edilmiştir. Çalışmada 500 elma için optimal durak sayısı 3 olarak bulunmuştur. Her bir durakta hava araçlarının elma toplama sürelerini optimize etmek için hazırlanan model Gurobi çözücüsü yardımıyla çözümlenip sonuçlara ulaşılmıştır. Çalışmanın sonucunda kara aracının her bir durakta ortalama bekleme süresi yaklaşı 439 sn olarak elde edilmiştir. Bu çalışma ileride yapılacak çalışmalara örnek teşkil edebilir. Akı1lı tarım, tüm bileşenleri ile birlikte uygulanabildiğinde girdilerin optimizasyonu yoluyla, çevre sorunlarına da büyük faydalar sağlayabilecektir. Dünya nüfusunun giderek artması ile ortaya çıkacak olan beslenme ve küresel kaynakların etkili kullanım sorunlarına etkili çözümler üretebilecektir.

\section{Kaynakça}

Bekhti, M., Achir, N., Boussetta, K., Abdennebi, M.,(2017). Drone Package Delivery: A Heuristic Approach for UAVs Path Planning and Tracking, EAI Endorsed Transactions on Internet of Things, Volume 3(9), 1-10.

Bezanson, J., Edelman, A., Karpinski, S. ve Shah, V. B. (2017). Julia: A Fresh Approach to Numerical Computing, SIAM Review, 59(1), 65-98.

Duman, B., ve Özsoy, K., (2019). Endüstri 4.0 Perspektifinde Akıllı Tarım (Smart Agriculture in Industry 4.0 Perspect1ve), 4th International Congress On 3d Printing (Additive Manufacturing) Technologies And Digital Industry, 11-14 Nisan 2019, Antalya, Türkiye, $540-555$.

Dunning, I., Huchette, J. ve Lubin, M. (2017). JuMP: A Modeling Language for Mathematical Optimization, SIAM Review, 59(2), 295-320. 
Eminoğlu, B., Öztürk, R., Acar, A. İ., Kalınkara, V. (2015). Meyve Hasadında Kullanılan Hasat Platformlarının Çalışma Koşullarının İyileştirilmesi Yönünden Değerlendirilmesi, Süleyman Demirel Üniversitesi Mühendislik Bilimleri ve Tasarım Dergisi, 3(3), 233-238. Ferrandez, S. M., Harbison, T., Weber, T., Sturges, R., \& Rich, R. (2016). Optimization of a Truck-Drone in Tandem Delivery Network Using K-Means and Genetic Algorithm, Journal of Industrial Engineering and Management, 9(2), 374-388.

Gurobi Optimization, L. (2018). Gurobi Optimizer. http://www.gurobi.com adresinden erişildi. Murray, Chase C., Chu, Amanda G. (2015). The Flying Sidekick Traveling Salesman Problem:

Optimization of Drone-Assisted Parcel Delivery, Transportation Research Part C: Emerging Technologies, Volume 54, 86-109.

Olivares, Víctor, Cordova, Felisa, Sepúlveda, Juan M. \& Derpich, Ivan. (2015). Modeling Internal Logistics by Using Drones on the Stage of Assembly of Products, Procedia Computer Science. Volüme 55, 1240-1249.

Şengöz, N., ve Özdemir, G. (2016). Temel Bileşenler Analizi ve K-Ortalama Kümeleme Yönteminin Birlikte Kullanımı: Bir Örnek Uygulama, Mehmet Akif Ersoy Üniversitesi Sosyal Bilimler Enstitüsü Dergisi, 8 (15), 85-94.

Tekin, A.B., (2013). Tarım Robotları, Tarım Makinaları Bilimi Dergisi, 9 (4): 273-278.

Tevel-tech (2019). https://www.tevel-tech.com/ adresinden 23.01.2020 tarihinde alınmıştır.

Tevel-tech (2019). https://patentswarm.com/patents/US20190227575A1 adresinden 23.01. $\underline{2020}$ tarihinde alınmıştır.

Topakcı, M. ve Ünal, İ. (2010). Hassas Tarımda Değişken Oranlı Uygulamalar, Tarımsal Mekanizasyon 26. Ulusal Kongresi, 22-23 Eylül, Hatay, Türkiye.

Wang, Xingyin \& Poikonen, Stefan \& Golden, Bruce. (2016). The Vehicle Routing Problem with Drones: Several Worst-Case Results, Optimization Letters. 11(4), 679-697. 